\title{
Experimental Investigation into the Resistance Characteristics of Trimaran and Pentamaran Configurations
}

\author{
Richard Benny Luhulima ${ }^{1}$, Sutiyo ${ }^{2}$, Muhammad Rizki Alia ${ }^{3}$, I Ketut Aria Pria Utama ${ }^{3 *}$ \\ ${ }^{1}$ Department of Naval Architecture, Faculty of Engineering, Universitas Pattimura, Jalan Ir. M. Putuhena, \\ Poka-Ambon 97234, Indonesia \\ ${ }^{2}$ Department of Naval Architecture, Faculty of Engineering and Marine Science, Universitas Hang Tuah, \\ Jalan Arief Rahman Hakim 150, Surabaya 60111, Indonesia \\ ${ }^{3}$ Department of Naval Architecture, Faculty of Marine Technology, Institut Teknologi Sepuluh Nopember, \\ Kampus ITS, Sukolilo, Surabaya 60111, Indonesia
}

\begin{abstract}
Research on the development of multihull vessels has investigated the breakdown of trimaran side hulls and produced a new type of vessel popularly known as a pentamaran. This study into the resistance characteristics of pentamarans was carried out using a towing tank belonging to the Institute Technology at Sepuluh Nopember in Surabaya, Indonesia. A test of trimaran resistance was included for comparison. The investigation focused on total resistance estimation and interference analysis for the two types of multihull vessels at separation-length ratios (S/Ls) of 0.2, 0.3 , and 0.4. The dominant resistance value for the pentamaran was higher than that for the trimaran, with an average of $5.2 \%$, due to the more complex interference between hulls. The average total resistance interference was $9.5 \%$ for the trimaran and $12.5 \%$ for the pentamaran.
\end{abstract}

Keywords: Experimental study; Pentamaran; Resistance; S/L ratio; Trimaran

\section{Introduction}

The use of multihull ships as passenger carriers has been common for the last 50 years, according to Insel and Molland (1992). Multihull vessels are more stable than single-hull vessels (Peng, 2001) and can provide larger deck areas than single-hull ships of the same length (Molland and Utama, 2002), (Samuel et al. 2015). Sahoo et al. (2007) reported that multihulls are safer than their monohull counterparts because of their greater and more easily maintainable transverse stability as well as their larger above-water capacities. The most interesting phenomenon is its ability to reduce wave-making resistance based on adjustments to the hull configuration and hull form (Iqbal and Samuel, 2017).

Most multihull ships are more seaworthy than their monohull counterparts, and ships with short waterplane areas exhibit high-performance seakeeping characteristics. The strength specificity of multihulls plays a vital role in defining transverse loads and preventing wet-bottom slamming in multihull vessels (Dubrovsky, 2009). A trimaran is a multihull vessel that consists of one main hull and two side-hulls, which are known as outriggers. The side hulls are smaller in size and positioned on either side of the main hull. Trimaran hulls are an advance on single hulls, intended to enhance a ship's speed while 
simultaneously reducing power requirements (Tupan and Luhulima, 2020). The increased allowable aspect ratio of these hulls makes them more energy efficient when operating at high speeds (Utama et al. 2021a).

The unique hull shape was designed by Nigel Gee and Associates Ltd. In the United Kingdom (Gee et al. 1997). The pentamaran is a slender, stabilized monohull that, compared to conventional monohull or catamaran designs, has the potential to reduce power consumption by up to $30 \%$ for large high-speed vessels. Ikeda et al. (2005) found that a pentamaran ferry outperformed a monohull ferry in terms of performance, dead weight, and deck area. The results suggested that, from an economic standpoint, pentamaran passenger ferries could replace monohull roll on/roll off (ro-ro) passenger ferries.

A ship's side hull is designed to meet certain stability standards (Luhulima et al. 2014). The use of four side hulls on a pentamaran can enhance stability for the rolling motion and ensure minimal resistance. Pentamaran ships offer the reduced resistance and maximized power needed to drive ships forward while maintaining high seakeeping qualities (Gee and Hawkins, 2005). A pentamaran is a monohull vessel that is stabilized by four side hulls-two on the starboard side and two on the port side. A ship's main hull is designed to have the lowest feasible resistance for a given displacement and speed (Sulistyawati et al. 2019).

Research on the resistance properties of trimarans and pentamarans relative to the interference effect is incomplete due to the large number of potential configurations for this type of vessel. The topic of trimaran hulls has attracted significant worldwide research attention and led to the possibility of unconventional maritime vehicles. A recent study proposed a pentamaran hull for passenger and vehicular transportation (Gee and Hawkins, 2005); however, published articles (Gee et al. 1997) regarding pentamarans provide little information about their hydrodynamic behavior in terms of resistance, which is vital for ensuring ships' hydrodynamic performance. because it is tied to ships' hydrodynamics. Pentamarans have interesting potential as water transportation vessels with slim hulls and long ship dimensions of mainhull. Each side hull supports both front and rear stability; hence, the most recent studies (Yanuar and Waskito, 2017) comparing trimaran and pentamaran vessel designs have focused on achieving optimal resistance characteristics across a range of speeds. Further investigation could provide a precise explanation for the related interference phenomena, which can affect vessel performance in certain cases. The present research on trimaran and pentamaran vessels considered lateral spacing and longitudinal side hulls. The scope of the study was limited to model resistance characteristics and the interference factor (IF) values for a specified Froude number (Fr) range (i.e., from low to moderate). These two types of resistance were considered essential among the various resistance components because interference phenomena impact both the wave-making resistance and viscous resistance of multihull vessels. This article provides an overview of the findings.

\section{Methods}

\subsection{Trimaran and Pentamaran Hull Configurations}

This research investigated trimaran and pentamaran models with varying lateral and longitudinal side-hull separations. The trimaran consisted of a main hull and two similar side hulls, whereas the pentamaran comprised a main hull and four identical side hulls. The body plans of the trimaran and pentamaran models are shown in Figure 1. Multihulls can be split into two categories for calculating the longitudinal variation of the distance between the hulls (Soeding, 1997): (1) a parallel hull configuration (unstaggered) and (2) a non-parallel hull configuration (staggered). 


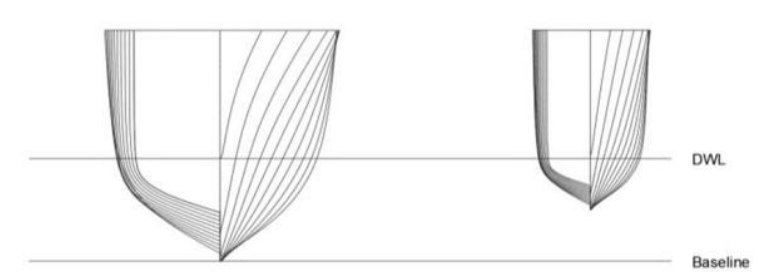

(a) Trimaran

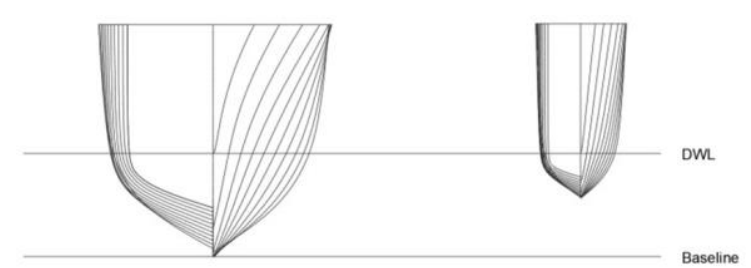

(b) Pentamaran

Figure 1 Body plans for the trimaran and pentamaran models

The distinction between staggered and unstaggered hulls is the hulls' longitudinal arrangement: a hull with the same uneven transverse position is referred to as an unstaggered hull. This study focused on unstaggered trimarans and pentamarans, and Table 1 presents the characteristics of the individual hull models.

Table 1 Particular dimensions of the ship models

\begin{tabular}{lcccc}
\hline \multicolumn{1}{c}{ Parameter } & Unit & Main Hull & $\begin{array}{c}\text { Side Hull } \\
\text { Trimaran }\end{array}$ & $\begin{array}{c}\text { Side Hull } \\
\text { Pentamaran }\end{array}$ \\
\hline LwL (length of water line) & $\mathrm{m}$ & 0.8000 & 0.4000 & 0.2770 \\
B (breadth) & $\mathrm{m}$ & 0.0892 & 0.0446 & 0.0352 \\
T (draft) & $\mathrm{m}$ & 0.0446 & 0.0223 & 0.0192 \\
WSA (wetted surface area) & $\mathrm{m}^{2}$ & 0.0542 & 0.0136 & 0.0122 \\
$\Delta$ (displacement) & $\mathrm{kg}$ & 1.2850 & 0.1600 & 0.0800 \\
\hline
\end{tabular}

The hull configuration has a significant impact on a ship's overall resistance. The distance between the centerlines of the side hull and the main hull is denoted by the symbol $\mathrm{S}$. $\mathrm{R}$ is the distance between the rear side-hull transom and the front side-hull transom. Meanwhile, $\mathrm{L}$ is the length of the waterline measured from the main hull.

The arrangement of trimaran and pentamaran hulls was investigated to compare and analyze the hull layouts of both vessels. The study examined two different vessel configurations, each of which was represented by a straightforward notation (see Table 2). Figure 2 illustrates the trimaran and pentamaran hull configurations.

\subsection{Resistance Calculations}

Ship designers can use dimensionless coefficients to compare drag test data with real ship data or to compare the performance of several ship types. Resistance data from a towing-tank test can be used to calculate a ship's original resistance (Manen and Oossanen, 1988). The model-ship correlation method recommended by ITTC-57 (ITTC, 2011) was utilized in this study to find the original resistance value for each ship, determined using Equation 1 as follows:

$$
C_{T}=\frac{R_{T}}{\frac{1}{2} \rho v^{2} S}
$$

where: $C_{T}$ is the total resistance coefficient, $R_{T}$ is the total resistance $(\mathrm{N}), \rho$ is the density of water $\left(998 \mathrm{~kg} / \mathrm{m}^{3}\right), v$ is velocity $(\mathrm{m} / \mathrm{s})$, and $S$ is the wetted surface area $\left(\mathrm{m}^{2}\right)$.

Fr was then defined using Equation 2 (Newman, 1977):

$$
F r=\frac{v}{\sqrt{g L}}
$$

where $\mathrm{Fr}$ is the Froude number, $v$ is the observed model speed, $g$ is gravity's acceleration, and $L$ is the model length. Air resistance and correlation allowance were not included in the present investigation because the ship model was tested in calm water. 
Table 2 Ship model test codes

\begin{tabular}{lc}
\hline \multicolumn{1}{c}{ Code } & Configuration \\
\hline Model A & Trimaran 0.2 S/L \\
Model B & Trimaran 0.3 S/L \\
Model C & Trimaran 0.4 S/L \\
Model D & Pentamaran 0.2 S/L \\
Model E & Pentamaran 0.3 S/L \\
Model F & Pentamaran 0.4S/L \\
Model MH & Main Hull \\
Model SHT & Side Hull Trimaran \\
Model SHP & Side Hull Pentamaran \\
\hline
\end{tabular}

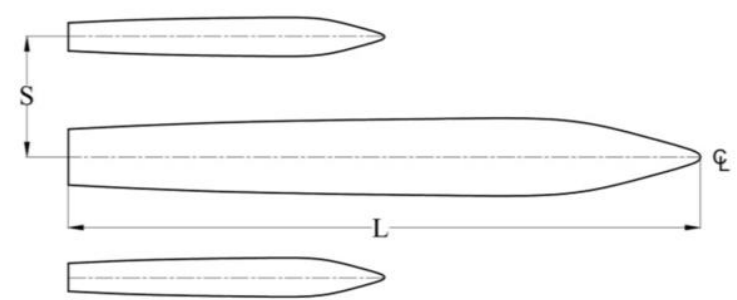

(a) Trimaran,

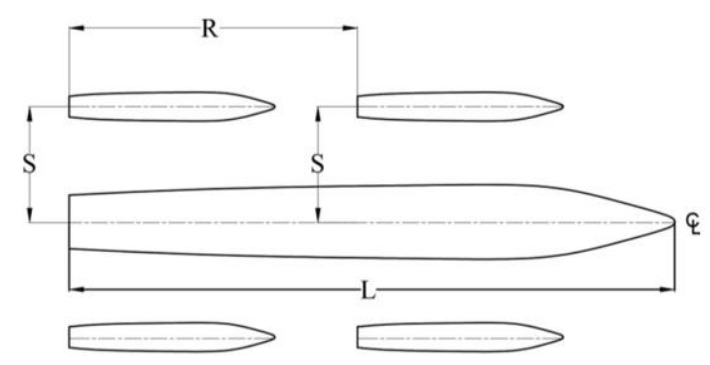

(b) Pentamaran

Figure 2 Trimaran and pentamaran hull configurations

The present research utilized model speed, configuration, and hull separation changes to observe interference phenomena. To quantify the interference phenomena, two test scenarios were developed: the first tested the multihull models separately, and the test results for each hull (main hull and side hull) were then summed to eliminate interaction between hulls (non-interference [NI]), as written in Equation 3. The second test scenario tested the full multihull model to evaluate the interactions between hulls and produce resistance interference values. The difference in resistance between individual and multihull vessels was called the interference phenomenon. The total resistance coefficient for the trimaran was defined using Equations 4 and 5:

$$
C_{T \text { multihull (NI) }}=C_{T \text { mainhull }}+n C_{T \text { sidehull }}
$$

where $C_{T \text { multihull (NI) }}$ is the total multihull resistance coefficient with no interference, $C_{T \text { mainhull }}$ is the total resistance coefficient for the main hull, and $C_{T}$ side_trimaran is the total resistance coefficient for the trimaran side hull.

$$
\begin{aligned}
C_{T \text { trimaran }}= & C_{T \text { mainhull }}+2 C_{T \text { side_trimaran }}+\Delta C_{T \text { trimaran }} \\
& =C_{T \text { trimaran }(N I)}+\Delta C_{T \text { trimaran }}
\end{aligned}
$$

where $C_{T \text { trimaran }}$ is the total resistance coefficient for the trimaran, $C_{T \text { mainhull }}$ is the total resistance coefficient for the main hull, $C_{T}$ side_trimaran is the total resistance coefficient for the trimaran side hull, $C_{T \text { trimaran(NI) }}$ is the total resistance coefficient for the trimaran noninterference, and $\Delta C_{T \text { trimaran }}$ is the difference in resistance coefficient between trimaran interference and non-interference. Similarly, for the pentamaran (see Equations 6 and 7):

$$
\begin{gathered}
C_{T \text { pentamaran }}=C_{T \text { mainhull }}+4 C_{T \text { side_pentamaran }}+\Delta C_{T \text { pentamaran }} \\
=C_{T \text { pentamaran }(N I)}+\Delta C_{T \text { pentamaran }}
\end{gathered}
$$

where $C_{T \text { pentamaran }}$ is the total resistance coefficient for the pentamaran, $C_{T \text { mainhull }}$ is the total resistance coefficient for the main hull, $C_{T \text { side_pentamaran }}$ is the total resistance 
coefficient for the pentamaran side hull, $C_{T \text { pentamaran(NI) }}$ is the total resistance coefficient for pentamaran non-interference, and $\Delta C_{T \text { pentamaran }}$ is the difference in resistance coefficient between the pentamaran interference and non-interference.

Furthermore, interference was defined as the difference between the total noninterference resistance and the interference of the multihull ship configuration (Sahoo et al. 2007). Despite the complexity of multihull total resistance components, interference effects can be observed experimentally. An IF measures the degree of interaction between the hulls of a multihull vessel (Zaghi et al. 2011) and is formulated according to Equation 8, as follows:

$$
I F=\frac{\Delta C_{T \text { multihull }}\left[C_{T \text { multihull }}-C_{T \text { multihull }(N I)}\right]}{C_{T \text { multihull }(N I)}}
$$

where $I F$ is the interference factor, $\Delta C_{T \text { multihull }}$ is the difference in resistance coefficient between multihull ship interference and non-interference $\left(C_{T \text { multihull }}-C_{T \text { multihull (NI) }}\right)$, and $C_{T \text { multihull (NI) }}$ is the total resistance coefficient for multihull non-interference.

\subsection{Towing-Tank Model}

\subsubsection{Setup model}

The ship models were made of fiberglass-reinforced plastic (FRP) and followed the ITTC-Recommended Procedure and Guidelines: Ship Model (ITTC, 2017) to ensure similarity and correlations between real vessels and the ship models. Molds for printing FRP were manufactured using a three-dimensional printing process. The trimaran and pentamaran models' structural integrity was rigorously examined to prevent structural bending or unevenness between individual hulls during towing. As a separation adjustment system, two transverse frames made of steel bars were utilized to strengthen the separation of the model, as shown in Figures 3a and 3b.

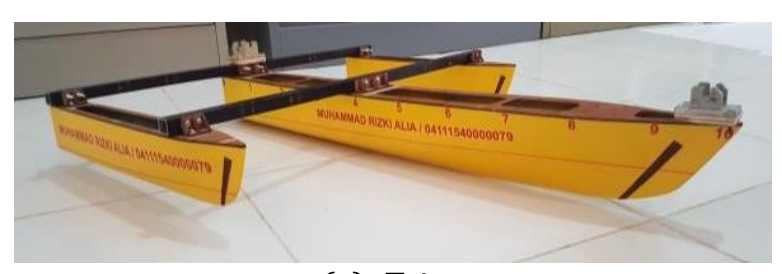

(a) Trimaran

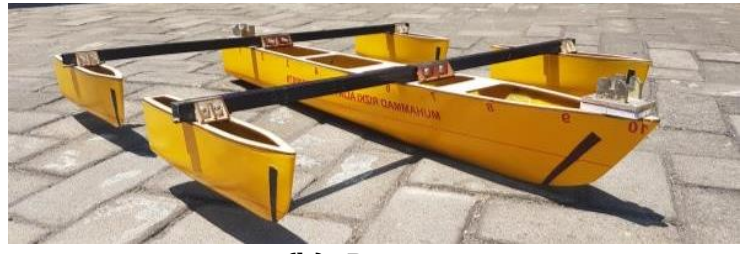

(b) Pentamaran

Figure 3 Experimental models

Each configuration was evaluated for certain Fr ranges (i.e., from low to high), and the results were all positive. Under fixed towing conditions, the ship model was towed in a water tank with $50 \mathrm{~m}$ length, $3 \mathrm{~m}$ width, $2 \mathrm{~m}$ depth, and a maximum towing-carriage speed of $4 \mathrm{~m} / \mathrm{s}$. Some of the main instruments for the experimental setup were as follows:

- a load cell transducer to calculate the total resistance of the running model

- a set of data acquisition instruments for processing and recording data from load cells

- a pair of turbulent strips to create turbulent flow around the model

The experimental setup also included some additional instruments. Instead of using the conventional technique for speed measurement, probes were placed in the model to measure the model's speed as it approached the critical frequency. The standards for the vessel and method performance, except the model speed measurements, accorded with the ITTC Recommended Procedures and Guidelines: Resistance Test (ITTC, 2011). The experimental setup is shown in Figure 4. The experiments were carried out in a calm water environment, with a specified amount of waiting time after each test to maintain the calmness of the water (Peng et al. 2010). 


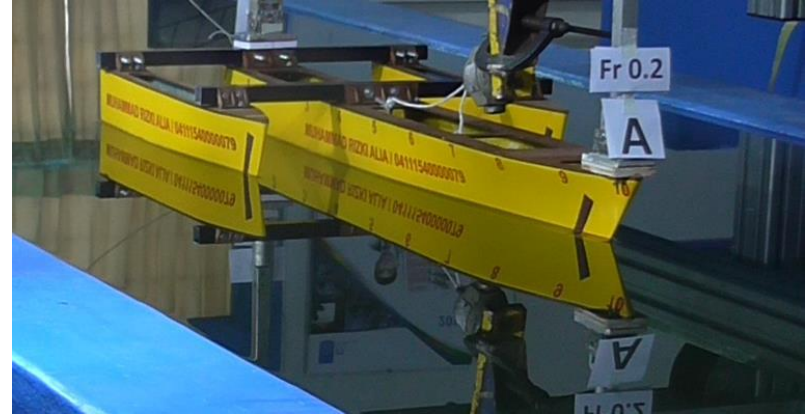

(a) Trimaran

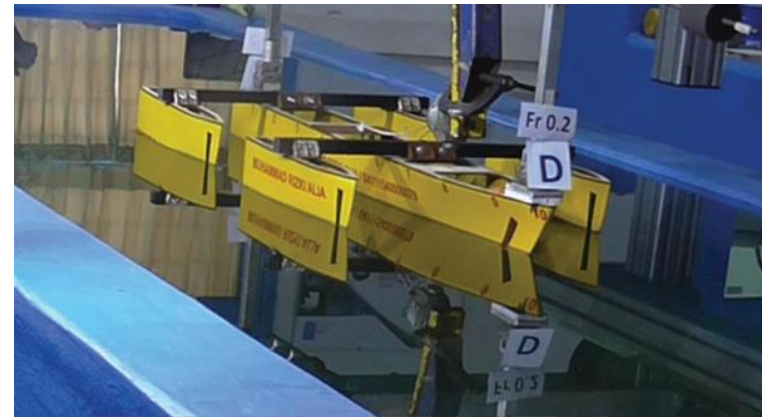

(b) Pentamaran

Figure 4 Towing-test models

Throughout all tests, in which the $F r$ was varied between values of $0.2-0.6$, a consistent ship-model speed was maintained.

A load cell transducer was used to determine the overall hull resistance. A load cell is a force transducer that operates according to the material deformation caused by applied mechanical stress. The magnitude of the mechanical stress is determined by the straininduced deformation. Strain occurs in a material's surface layer and may be detected using a strain sensor or strain gauge. A strain gauge is a passive transducer that transforms a mechanical shift into a change in resistance and subsequently into actuation data. The difference in resistance between each model variation was clearly apparent. Apart from using load cell measurements, interference phenomena can be captured visually using two cameras mounted in front of and behind the model, as illustrated in Figure 5.
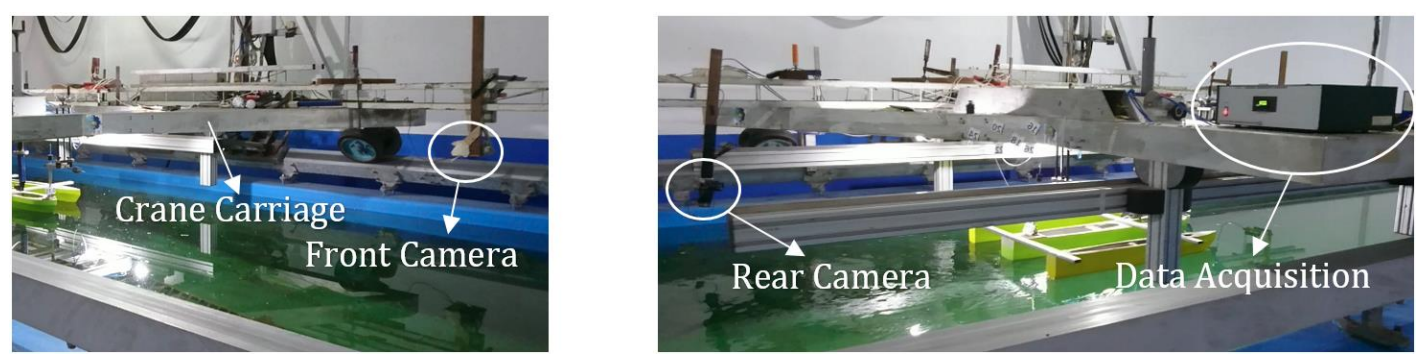

Figure 5 Setup of test model equipment

\subsubsection{Calibration procedure}

Calibration is the process of verifying and adjusting the accuracy of test equipment by comparing it to standards or benchmarks (Utama et al. 2021b). Calibration is required to guarantee that a tool's measurements are accurate and repeatable. A load cell (Figure 6a) measured the resistance of the ship model to translational motion. The load-cell reading produced an electrical signal, which was amplified with an amplifier and recorded on a strip chart recorder.

The load-cell calibration procedure was carried out under calm sea conditions by connecting a synthetic fiber rope to the ship model's rear guiding shaft (Figure 6b) and to a weight at the other end. The rope was then attached to a pulley located at one end of the test pool, and the weights were allowed to hang freely, as shown in Figure 6c. The strip chart recorder then captured the readings. The comparison of the actual mass value of the load and the mass value obtained using the strip chart recorder was utilized as a reference for reading the towing-test data.

The value for the rated load indicated that the maximum load that could be measured by the load cell was $2 \mathrm{~kg}$. Meanwhile, the rated output is the difference between a load cell with no load and a load cell with a given rated load or maximum load. We found that the 
load cell would work well with a given excitation voltage of $2 \mathrm{~V}$ and a load cell capability reading of $0-2 \mathrm{~kg}$.

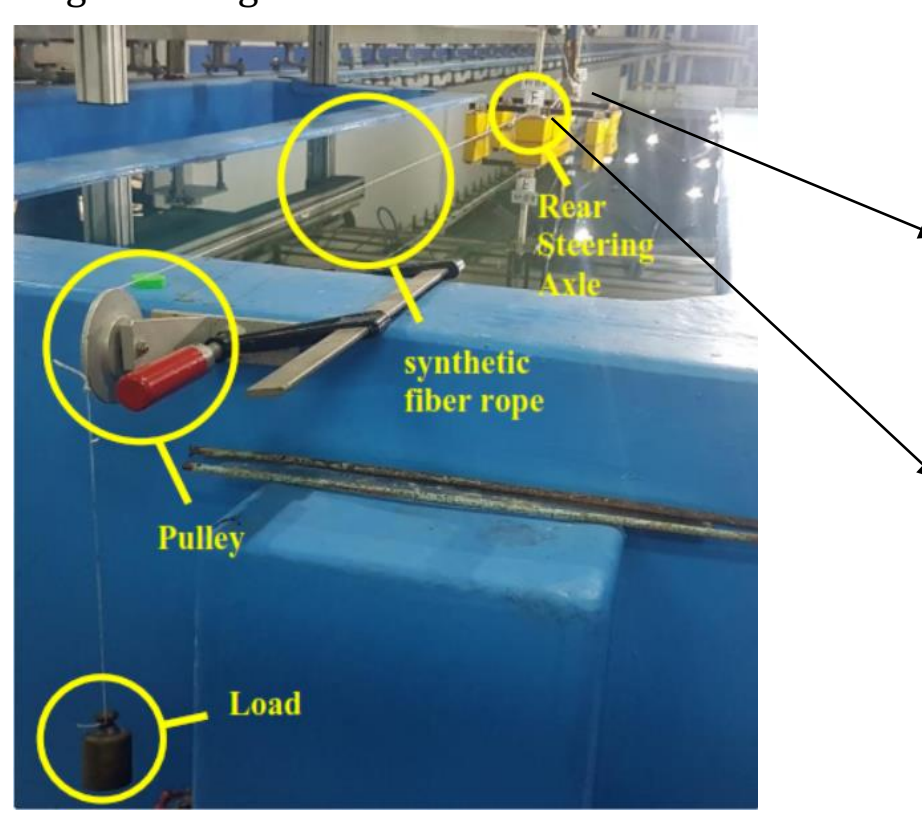

(c) Model test calibration

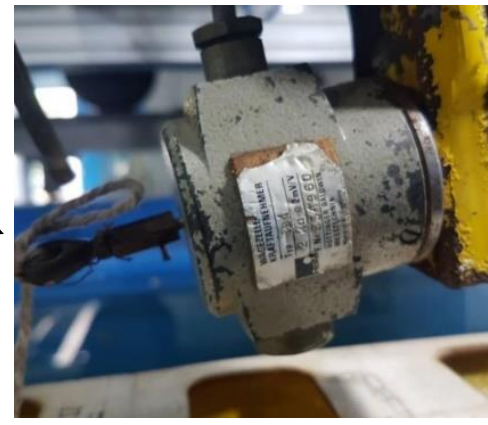

(a) Load Cell

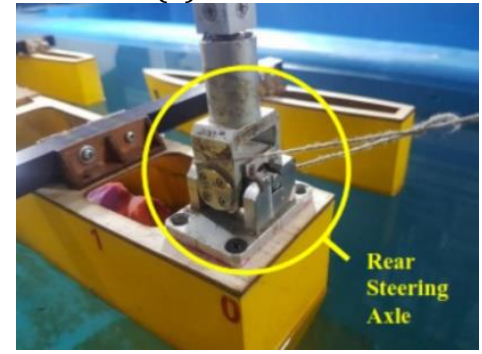

(b) Rear steering axle

Figure 6 Tools and calibration settings

\subsubsection{Uncertainty analysis for testing resistance}

Special consideration was given to the integration of uncertainty estimates in all steps of the experimental procedure. The guide to the expression of uncertainty in measurement (GUM) approach is used for hydrodynamic testing, and specific factors must be considered for the uncertainty analysis of ship resistance (ITTC, 2014b). Significant uncertainties in ship model resistance testing include the following (ITTC, 2014a) :

1. wetted surface area (water-immersed hull) geometry

2. speed (towing carriage)

3. tank-water temperature

4. dynamometer (resistance gauge)

5. repeated test

The displacement volume of the ship model represented the wetted surface area of the hull, and the uncertainty associated with the hull geometry was calculated using Equation 9:

$$
u_{1}^{\prime}\left(R_{T}\right)=u^{\prime}(S)=\frac{2}{3} u^{\prime}(\Delta)
$$

where $u^{\prime}(S)$ is the uncertainty component of the wetted surface area of the ship model, and $u^{\prime}(\Delta)$ is the uncertainty component of the displacement volume of the ship model.

The uncertainty of the velocity of the towing carriage was calculated quantitatively using Equation 10:

$$
u_{2}^{\prime}\left(R_{T}\right)=2 u^{\prime}(V)
$$

where $u^{\prime}(V)$ is the uncertainty of the towing speed.

The relative uncertainty associated with the viscosity of water as a function of temperature was determined using Equation 11:

$$
u_{3}^{\prime}\left(R_{T}\right)=\frac{C_{F}}{C_{T}} \frac{0.87}{\log _{10} R e-2} u^{\prime}(v)
$$


where $C_{F}$ is the friction coefficient, $C_{T}$ is the total resistance coefficient, $R e$ is the Reynold's number, and $u^{\prime}(v)$ is the uncertainty component of the water viscosity affected by temperature.

The resistance uncertainty component arising from the dynamometer calibration was evaluated using standard error estimation (SEE), which was calculated using Equation 12:

$$
u_{4}^{\prime}\left(R_{T}\right)=S E E
$$

The standard uncertainty component of a single test could be estimated using Equation 13:

$$
u_{5}^{\prime}\left(R_{T}\right)=\frac{s_{d e v}}{R_{T}}
$$

All significant uncertainty components $\left(u_{c}^{\prime}\right)$ relating to the total resistance were combined and analyzed to determine the overall standard uncertainty using the RSS (root sum squared) method with Equation 14:

$$
u_{c}^{\prime}=\sqrt{\left(u_{1}^{\prime}\right)^{2}+\left(u_{2}^{\prime}\right)^{2}+\left(u_{3}^{\prime}\right)^{2}+\left(u_{4}^{\prime}\right)^{2}+\left(u_{5}^{\prime}\right)^{2}}
$$

\section{Results and Discussion}

\subsection{Uncertainty Resistance Test Analysis}

The resistance test for trimaran model A $(S / L=0.2)$ was carried out using the towing tank at the ITS Hydrodynamic Laboratory in Surabaya, Indonesia. Model testing was carried out twice at each speed. The resistance test at a speed of $0.560 \mathrm{~m} / \mathrm{s}-1.680 \mathrm{~m} / \mathrm{s}$ was equivalent to the Froude number $0.2-0.6$ based on Equation 2. The measured temperature during the test was $27.1^{\circ} \mathrm{C}$. Table 3 shows the testing of the trimaran A model at Froude numbers of $0.2-0.6$. Based on the test results for the ship model, the value of the total drag coefficient $\left(C_{T}\right)$ was calculated using Equation 1. A graph of the total resistance coefficient $\left(C_{T}\right)$ against the Froude number $(\mathrm{Fr})$ showed that as the trend of the total drag coefficient increased, the resistance experienced by the ship also increased, as shown in Figure 7. The total resistance of the ship depended on the total drag coefficient.

Table 3 Total resistance coefficients for trimaran Model A

\begin{tabular}{cccccc}
\hline & TEST I & \multicolumn{3}{c}{ TEST II } \\
\hline Fr & $\mathrm{v} \mathrm{(m/s)}$ & $\mathrm{C}_{\mathrm{T}}$ & $\mathrm{Fr}$ & $\mathrm{v}(\mathrm{m} / \mathrm{s})$ & $\mathrm{C}_{\mathrm{T}}$ \\
\hline 0.200 & 0.560 & 0.0074 & 0.202 & 0.565 & 0.0075 \\
0.300 & 0.840 & 0.0087 & 0.299 & 0.837 & 0.0088 \\
0.400 & 1.120 & 0.0084 & 0.396 & 1.109 & 0.0085 \\
0.500 & 1.400 & 0.0104 & 0.505 & 1.413 & 0.0105 \\
0.600 & 1.680 & 0.0089 & 0.605 & 1.693 & 0.0090 \\
\hline
\end{tabular}

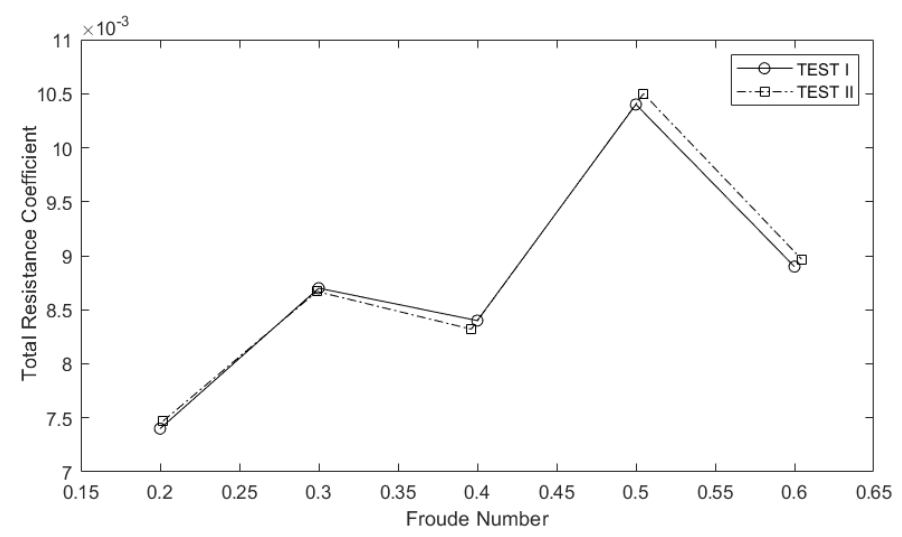

Figure 7 Comparison of total resistance coefficients between TEST I and TEST II for trimaran Model A 
Table 4 Uncertainty values obtained from the resistance tests (\%)

\begin{tabular}{cccccc}
\hline Parameter & Fr $=0.2$ & Fr $=0.3$ & Fr $=0.4$ & Fr $=0.5$ & Fr $=0.6$ \\
\hline Wetted surface area & 0.130 & 0.130 & 0.130 & 0.130 & 0.130 \\
Speed & 0.800 & -0.500 & -0.700 & 0.800 & 0.600 \\
Water temperature & 0.010 & 0.010 & 0.015 & 0.015 & 0.020 \\
Dynamometer & 0.010 & 0.015 & 0.020 & 0.015 & 0.025 \\
Single test (deviation) & 0.379 & 0.281 & 0.478 & 0.378 & 0.279 \\
Combined mean & 0.895 & 0.588 & 0.985 & 0.895 & 0.675 \\
\hline
\end{tabular}

The ITTC procedure was utilized to evaluate the uncertainty of the model-scale resistance testing in towing tanks. Table 4 shows the total uncertainty for a single test. The uncertainty values calculated using Equations 9-13 showed that, for the single test, the largest uncertainty value compared to other variables was $0.478 \%$, and the value was 0.985 $\%$ for the combined mean at Froude number 0.4 .

\subsection{Total Resistance Coefficient}

Figure 8 shows the test results for the trimaran and pentamaran ship models. The trimaran ship's resistance with $\mathrm{S} / \mathrm{L}=0.2$ (Model $\mathrm{A}$ ) was more dominant than that of the other trimaran model variations. Model $C$ had the lowest resistance value for the trimaran (combined hull), with a variation of $\mathrm{S} / \mathrm{L}=0.4$. Models $\mathrm{A}, \mathrm{B}$, and $\mathrm{C}$ had more resistance than the individual trimaran model (without interference), with average differences of $16.2 \%$, $7.5 \%$, and $5.0 \%$, respectively.

The pentamaran model (integrated hull) had roughly the same resistance trend; however, the trend was more pronounced for the D model, which had higher resistance than the other models. Model D had an average resistance differential of $15.9 \%$ compared to the individual pentamaran model (without interference). Compared to the individual pentamaran model (without interference), the $\mathrm{E}$ and $\mathrm{F}$ models showed approximately $12.1 \%$ and $9.6 \%$ differences in resistance, respectively. The pentamaran model exhibited fluctuating resistance below $F r$ 0.6, which was consistent with the results reported by Yanuar and Sulistyawati (2018).

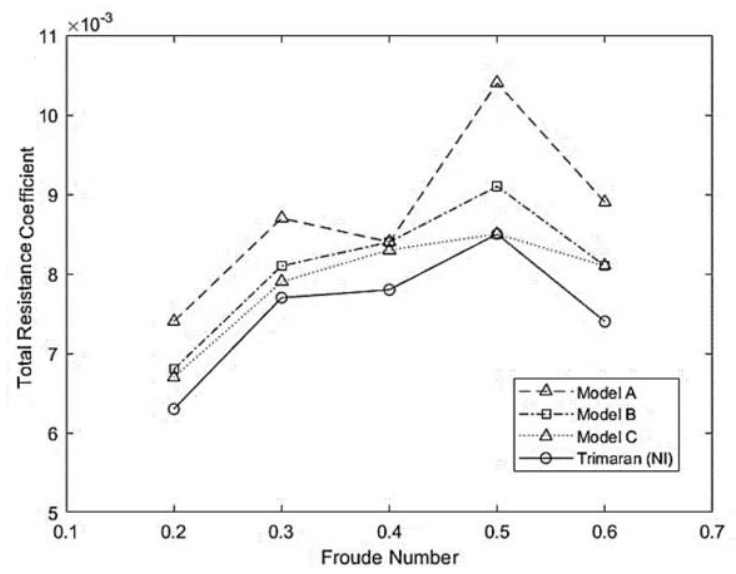

(a) Trimaran

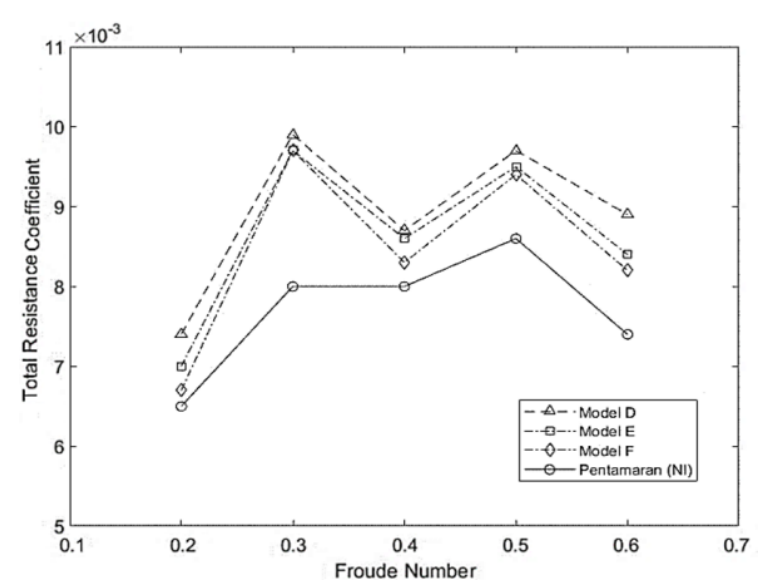

(b) Pentamaran

Figure 8 Total resistance coefficients

Trimaran models (combined hulls) generally have greater resistance than separate trimaran models due to the influence of interference on the design of trimaran models. Interference occurs because of the interaction between waves and the geometry of the hull (the form factor). The effect of waves during the trimaran test was apparent and had a significant impact on the amount of added resistance. In this case, at $\mathrm{S} / \mathrm{L}=0.2$ (Model A), a 
crash between the waves was created by the main hull on the side hull of the trimaran model, resulting in interaction between the two waves, as shown in Figure 9a. For Model C with $\mathrm{S} / \mathrm{L}=0.4$ (Figure 9b), at the same speed, there was little or no wave interaction and, consequently, no increase in resistance. During this trimaran test, the wave interaction had a negative effect, since it produced a significant increase in model resistance, particularly at $F r=0.5$. The differences in interference for each trimaran ship variation are shown in Figure 10 .

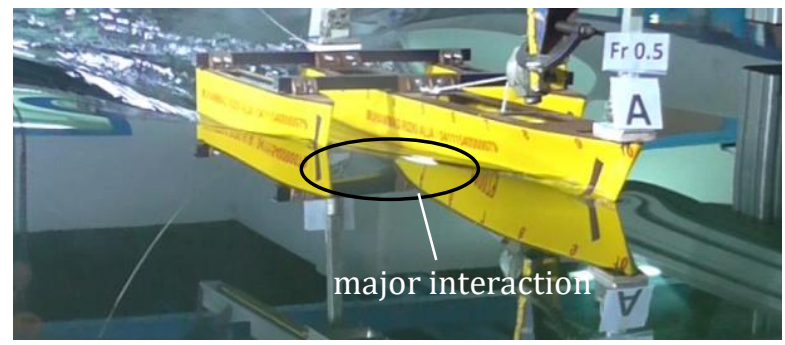

(a) Trimaran Model A

Figure 9 Model test at $\mathrm{Fr}=0.5$

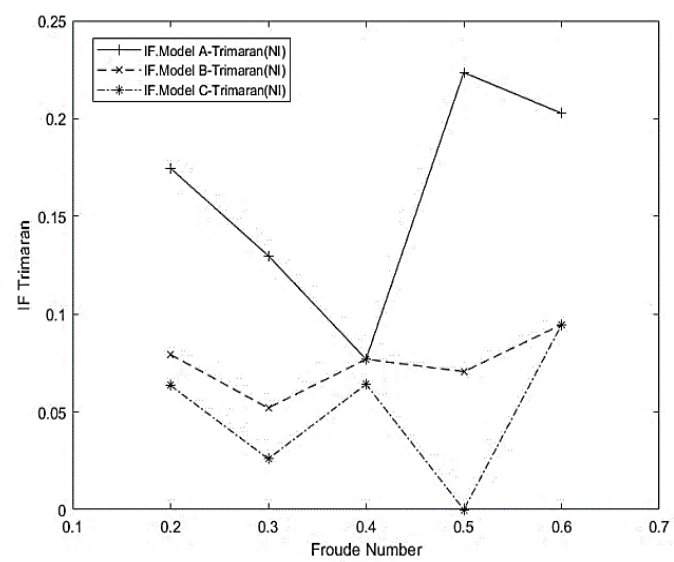

(a) Trimaran

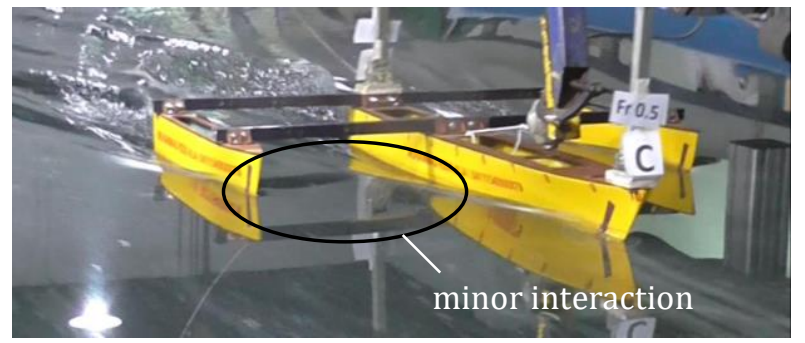

(b) Trimaran Model C

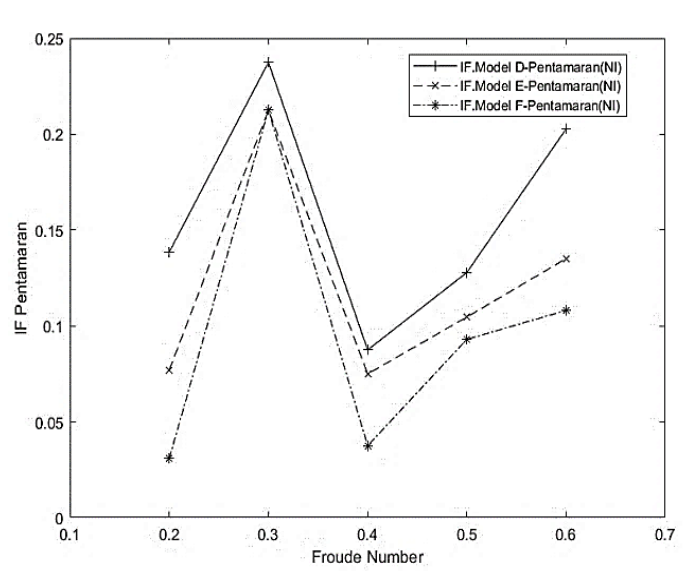

(b) Pentamaran

Figure 10 Interference factor

Figure 11 illustrates the difference in interference between the trimaran and pentamaran ship variants compared to the others and shows that resistance increased significantly for Model D with $F r=0.6$ compared to Model F. Model D, with a variation of $\mathrm{S} / \mathrm{L}=0.2$, displayed a complex wave interaction phenomenon, with the waves for the three hulls-the main hull, front hull, and rear hull-interacting. In general, for all pentamarans, waves had the same impact on one another; however, the interaction exhibited by model D (Figure 11a) was more complex. As illustrated in Figure 11b, the resistance for model $\mathrm{F}$ decreased as a result of reduced wave interactions between the hulls.

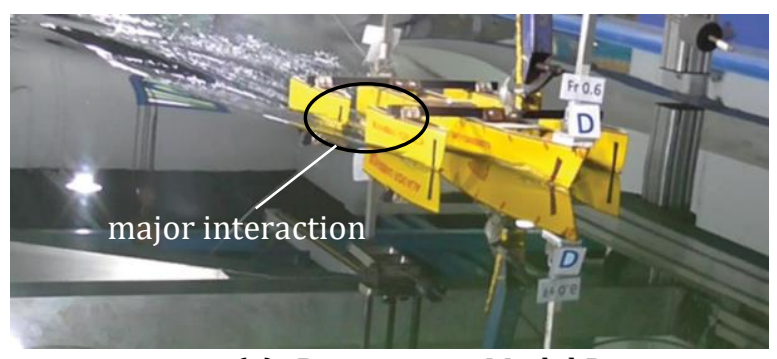

(a) Pentamaran Model D

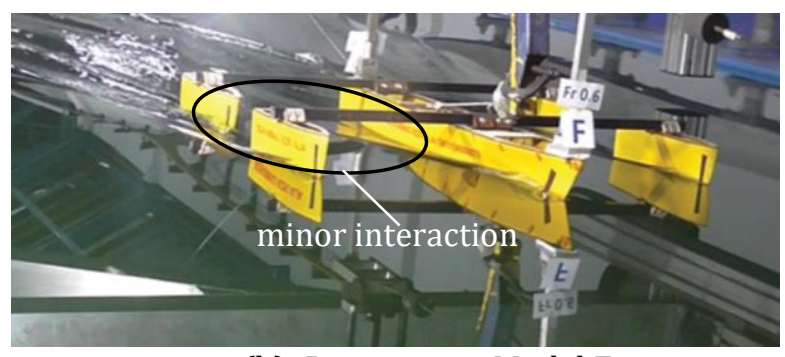

(b) Pentamaran Model F

Figure 11 Model tests at $\mathrm{Fr}=0.6$ 


\subsection{Resistance of the Trimaran and Pentamaran}

Comparisons between the resistances of the trimaran and pentamaran are shown in Figure 12. In general, the resistance fluctuation characteristics of the two multihull models were the same; thus, for $F r=0.3$ and 0.5 , both multihull models had increasing resistance. Interactions for the pentamaran were more complex, resulting in a higher dominant resistance value than for the trimaran. The trimaran and pentamaran had different average resistances under identical conditions, as follows: Model A-Model D, 2.1\%; Model B-Model E, 6.6\%; and Model C-Model F, 6.9\%.

Model A, with $F r=0.5$, had greater resistance than Model D with the same $F r$ due to the waves generated by the main hull reaching the entire full side hull and making the increase in resistance more significant. The pentamaran had the advantage of a smaller rear side hull; hence, the additional resistance was less than for the trimaran. Under this condition, the difference in the resistance for the trimaran was $6.7 \%$ greater than that for the pentamaran.

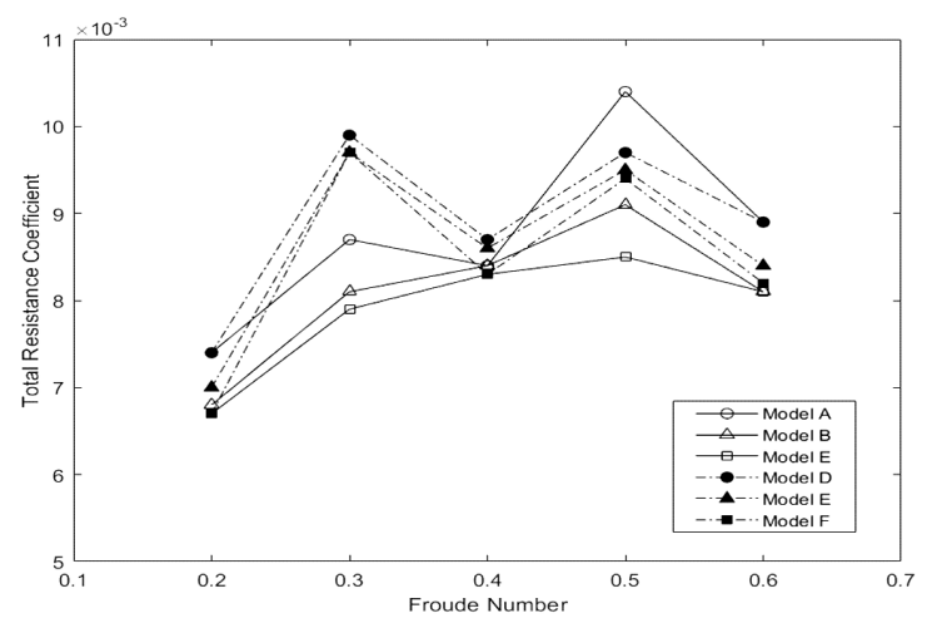

Figure 12 Difference in total resistance coefficients between the trimaran and pentamaran

Mutilhull ships of both types, with different variations of S/L for each model, had an ideal speed of $\mathrm{Fr}=0.4$; however, both models had similar critical velocities at $\mathrm{Fr}=0.3$ and 0.5 , respectively. This was also found in Utama et al. (2021a) research on trimaran configurations, as well as in the research conducted by Yanuar and Sulistyawati (2018) on pentamaran configurations. Trimaran models typically have a lower resistance coefficient than pentamaran models; however, the trimaran Model A ship experienced a significant increase in drag, which, at $F r=0.5$, was greater than the other variations and thus required special consideration.

\section{Conclusions}

The current study made fairly good predictions of resistance according to the provisions of the ITTC procedure. The resistance testing was carried out using two types of multihull vessels (a trimaran and a pentamaran) with variations of $F r$ and S/L. Several notable results were obtained from the series of experiments. Both multihull vessels with variation $S / L=0.2$ had greater resistance than other variation models. The difference was quite significant between the individual and combined hulls with a variation of $\mathrm{S} / \mathrm{L}=0.2$ (i.e., an average of $16.2 \%$ for the trimaran and $15.9 \%$ for the pentamaran). The trimaran model's interference was significant at $F r=0.5$, whereas interference for the pentamaran 
model occurred at $F r=0.3$. The pentamaran's dominant resistance value was greater than that of the trimaran due to the more complex interactions between the hulls.

A benchmark uncertainty analysis for an experimental test of Trimaran Model A was carried out for $\mathrm{Fr}=0.2-0.6$ and demonstrated reasonable agreement. The uncertainty values for the variables that affected the test results revealed uncertainty values for five variables that were the source of experimental errors: wet surface, speed, temperature, and single test. Quantitative analysis gave the highest uncertainty value of $0.478 \%$ for a single test component and $0.985 \%$ for the combined mean. The smallest uncertainty value was for the temperature component.

\section{Acknowledgements}

The authors gratefully acknowledge financial support from the Institut Teknologi Sepuluh Nopember for this work, under project scheme of the Publication Writing and IPR Incentive Program (PPHKI) No. T/2029/IT2/HK.00.01/2021.

\section{References}

Dubrovsky, V.A., 2009. Multi-hulls: New Options and Scientific Developments. Ships and Offshore Structures, Volume 5(1), pp. 81-92

Gee, N., Dudson, E., Marchant, A., Steiger, H., 1997. The Pentamaran: A New Hull Concept for Fast Freight and Car Ferry Applications. In: $13^{\text {th }}$ Fast Ferry International Conference, $25^{\text {th }}-27^{\text {th }}$ February. Singapore

Gee, N., Hawkins, C., 2005. Applications of the Pentamaran Hull Form for Fast Sealift and Freight Applications. Avaliabel Online at https://dokumen.tips/documents/applications-of-the-pentamaran-hull-form-forfast-sealift-and-freight-applications.html, Accessed on July 9, 2021

Ikeda, Y., Nakabayashi, E., Ito, A., 2005. Concept Design of a Pentamaran Type Fast RoRo Ship. Journal of the Japan Society of Naval Architects and Ocean Engineers, Volume 1, pp. 35-42

Insel, M., Molland, A.F., 1992. An Investigation Into Resistance Components of High Speed Displacement Catamarans. The RINA. UK., Volume 134, pp. 1-20

Iqbal, M., Samuel, S., 2017. Traditional Catamaran Hull Form Configurations that Reduce Total Resistance. International Journal of Technology, Volume 8(1), pp. 85-93

ITTC, 2011. ITTC - Recommended Procedures and Guidelines - Resistance Test (7.5-02-0201). In: 26 International Towing Tank Conference, 28 August-13 September, Brazil. ittc.info/media/1217/75-02-02-01.pdf

ITTC, 2014a. Example for Uncertainty Analysis of Resistance Tests in Towing Tanks (7.502-02-02.1). In: 27th International Conference Towing Tank, 31 August-5 September. Denmark

ITTC, 2014b. Recommended Procedures and Guidelines: General Guideline for Uncertainty Analysis in Resistance Tests (7.5-02-02-02 (Revision 02). In: 27th International Conference Towing Tank, 31 August-5 September. Denmark

ITTC, 2017. ITTC Recommended Procedures and Guidelines: Ship Model. In: 28 ${ }^{\text {th }}$ International Towing Tank Conference, Wuxi, China, September 17-22, pp. 1-9

Luhulima, R.B., Setyawan, D., Utama, I.K.A.P., 2014. Selecting Monohull, Catamaran and Trimaran as Suitable Passenger Vessels Based on Stability and Seakeeping Criteria. In: The 14th International Ship Stability Workshop (ISSW), 29 September-01 October 2014, Malaysia

Manen, J.D., Oossanen, P., 1988. Principles of Naval Architecture Second Revision Volume II- 
Resistance, Propulsion and Vibration (Edward V. Lewis (ed.)), pp. 197-205

Molland, A.F., Utama, I.K.A.P., 2002. Experimental and Numerical Investigations into the Drag Characteristics of a Pair of Ellipsoids in Close Proximity. In: Proceedings of the Institution of Mechanical Engineers, Part M: Journal of Engineering for the Maritime Environment, Volume 216(2), pp. 107-115

Newman, J.N., 1977. Marine Hydrodynamics. 40th Anniversary Edition, MIT Press, pp. 2-3

Peng, H., 2001. Numerical Computation of Multi-Hull Ship Resistance and Motion [Dalhousie University]. Avaliable Online at https://dalspace.library.dal.ca//handle/10222/55750, Accessed on July 9, 2021

Peng, H., Qiu, W., Hsiung, C.C., 2010. Measuring Wave Resistance of High-Speed Multi-Hull Ship with a Small Towing Tank. In: 29th American Towing Tank Conference, August 1113, USA

Sahoo, P.K., Salas, M., Schwetz, A., 2007. Practical Evaluation of Resistance of High-Speed Catamaran Hull Forms-Part I. Ships and Offshore Structures, Volume 2(4), pp. 307-324

Samuel, Iqbal, M., Utama, I.K.A.P., 2015. An Investigation into the Resistance Components of Converting a Traditional Monohull Fishing Vessel into Catamaran Form. International Journal of Technology, Volume 6(3), pp. 432-441

Soeding, H., 1997. Drastic Resistance Reductions in Catamarans by Staggered Hulls. In: Fourth International Conference on Fast Sea Transportation (FAST '97), Volume 1, 2123 July, Australia

Sulistyawati, W., Yanuar., Pamitran, A.S., 2019. Warp-Chine on Pentamaran Hydrodynamics Considering to Reduction in Ship Power Energy. Energy Procedia, Volume 156, pp. 463468

Tupan, J., Luhulima, R.B., 2020. A Comparison of Monohull, Catamaran, Trimaran Vessels based on Operational Review of Fuel Use. International Journal of Engineering Research \& Technology (IJERT), Volume 09(12), pp. 431-436

Utama, I.K.A.P., Sutiyo, Suastika, I.K., 2021a. Experimental and Numerical Investigation into the Effect of the Axe-Bow on the Drag Reduction of a Trimaran Configuration. International Journal of Technology, Volume 12(3), pp. 527-538

Utama, I.K.A.P., Purnamasari, D., Suastika, I.K., Nurhadi, Thomas, G., 2021b. Toward Improvement of Resistance Testing Reliability. Journal of Engineering and Technological Sciences, Volume 53(2), pp. 201-210

Yanuar., Sulistyawati, W., 2018. Pentamaran Configuration Design with Modeling Hull form for Resistance Minimization. In: IOP Conference Series: Earth and Environmental Science, Volume 105(1)

Yanuar., Waskito, K.T., 2017. Experimental Study of Total Hull Resistance of Pentamaran Ship Model with Varying Configuration of Outer Side Hulls. Procedia Engineering, Volume 194, pp. 104-111

Zaghi, S., Broglia, R., Di Mascio, A., 2011. Analysis of the Interference Effects for High-Speed Catamarans by Model Tests and Numerical Simulations. Ocean Engineering, Volume 38(17-18), pp. 2110-2122 